Discussion Paper No. $\quad 581$

\title{
AN EMPIRICAL STUDY OF ALCOHOLIC CONSUMPTION AND LABOR PRODUCTIVITY IN JAPAN
}

\author{
Masayo Sato \\ and \\ Yasushi Ohkusa
}

May 2003

The Institute of Social and Economic Research

Osaka University

6-1 Mihogaoka, Ibaraki, Osaka 567-0047, Japan 
Discussion Paper No. $\quad 581$

\title{
AN EMPIRICAL STUDY OF ALCOHOLIC CONSUMPTION AND LABOR PRODUCTIVITY IN JAPAN
}

\author{
Masayo Sato \\ and \\ Yasushi Ohkusa
}

May 2003

The Institute of Social and Economic Research

Osaka University

6-1 Mihogaoka, Ibaraki, Osaka 567-0047, Japan 


\title{
An Empirical Study of Alcoholic Consumption and Labor Productivity in Japan
}

\author{
Masayo Sato \\ National Institute of Population and Social Security Research \\ and \\ Yasushi Ohkusa \\ Institute of Social and Economic Research, Osaka University
}

JEL Classifications:I12,I18,J31

Keywords: Alcoholic Consumption, Labor Productivity, Addiction, Income Effect, Health Promotion Policy, Health Japan 21, Policy Evaluation

Correspondence: Yasushi Ohkusa, ISER, Osaka University, 6-1 Mihogaoka Ibaraki Osaka, Japan

Tel:+81-6-6879-8566 Fax:+81-6-6878-2766

e-mail:ohkusa@iser.osaka-u.ac.jp 


\begin{abstract}
This paper examines the relationship between labor productivity and alcohol consumption based on research conducted with a limited sample of workers who drink alcohol. Estimation results show that in the case of males, the amount of alcohol consumed significantly raises labor productivity, with an elasticity of approximately 0.13 . In females, we cannot reach the firm conclusion. Conversely, the reverse relationship between labor productivity and alcohol consumption cannot be confirmed. Moreover, an awareness of appropriate alcohol consumption supports the sixth strategy of the Health Japan 21 policy, which is to reduce national alcohol consumption by about $20 \%$.
\end{abstract}




\section{Introduction}

The study of alcohol consumption is a contentious issue in the research field of addictive behaviors other than smoking. The main problem is in the relationship between labor supply and drinking behavior. There are currently a large number of investigations into this problematic relationship in the United States.

Unfortunately, the results are mixed. That is, problem drinking does not seem to influence employment (Benham and Benham(1982), Kenkel and Ribar(1994), Feng, Zhou, Butler, Booth and French(2001)). Regarding the effect of problem drinking on income, Berger and Leigh(1988), Bryant, Samaranayake and Whilhite(1993), French and Zarkin(1995), and Zarkin, French and Mroz et al.(1998) found that drinkers earned more than non-drinkers. Conversely, Kenkel and Ribar(1994), French and Zarkin(1995), and Mullahy and Sindelar(1993) found that heavy drinkers' wages or income were lower than those of light drinkers.

Moreover, from the macroeconomic perspective, Ruhm(1995) and Freeman(1999) confirmed that alcohol consumption moves pro-cyclically; i.e., it increases during an economic boom. On the other hand, Thomas(2001) concluded that the stress from anxiety over being unemployed in a period of recession raises the levels of alcohol consumption. The different conclusions of these two research projects are probably attributable to the type of data used. That is, the former used macro data and the latter used micro data.

The relationship between labor productivity and drinking is emphasized in the Health Japan 21 health promotion policy in Japan (The Committee for Health Japan 21(2000)). It is similar to Healthy People 2010 in the United States. This policy declares the following targets in a bid to reduce problem drinking:

- a $20 \%$ reduction in the number of heavy drinkers, 
- the elimination of drinking among minors, and

- the spread of public health knowledge about moderate and appropriate drinking.

This paper evaluates the Health Japan 21 policy from the viewpoint of health economics. Firstly, it checks the reliability of the relationship between labor productivity and drinking. As mentioned above, it has been investigated in many countries, but is yet to be studied in Japan. For our research, we focus on a sample of workers who drink alcohol.

It is a truism to say that labor productivity and drinking are simultaneously determined. That is, alcohol consumption may decrease (or rise) labor productivity ceteris paribus, but labor productivity, which is measured by wage or labor income, raises alcohol consumption if it is a normal good. Hence, we have to estimate these relationships by using the simultaneous equation system.

Secondly, this paper checks the effectiveness of the third point emphasized in the policy targets. In other words, we investigate how the diffusion of such knowledge reduces alcohol consumption. It is well known that knowledge of the harm of smoking does not affect the behavior of smokers in Japan (Sato and Ohkusa(2002)). Hence, it may also be the case that knowledge of moderate and appropriate drinking will not affect drinking behavior. Incidentally, Health Japan 21 also declares its intention to spread the knowledge of harm from smoking as a policy target.

\section{Data}

The data were obtained from a survey conducted in May 2001 in Japan. Of the total 1300 questionnaires distributed, 1024 were completed and returned. Concerning alochol consumtion, the questionnaires ask how much they drink 
alochol in average by unit of pure alcohol. Other important information collecting in this survey are as follows.

Knowledge of the harm of alcohol depends on the answer to the following question:

"How many drinks a day do you think is harmful for your health generally with respect to sake? One drink of sake $(180 \mathrm{ml})$ is equivalent to a medium bottle of beer $(500 \mathrm{ml})$, double shots of whiskey or brandy $(60 \mathrm{ml})$, one drink $(180 \mathrm{ml})$ of shochu of $35 \%$, or one glass of wine (120ml)."

The level cited as harmful for health in Health Japan 21 is one drink of sake, which is equivalent to 20g pure alcohol (Tsugane, Fahey, Sasaki, et al.(1999), Holman, English, Milne, et al.(1996)).

Two levels of knowledge about the effects of alcohol on health are defined here. The first definition is rigorous; that is, only those who answer exactly one drink of sake have the required knowledge. The second definition is somewhat broad; that is, those who answer less than or equal to one drink of sake have the required knowledge. Hereafter, we call the former definition rigorous and the latter definition broad. The rigorous definition means that those who excessively evaluate the harm of alcohol do not have the required knowledge, although the broad definition includes them together with well-informed persons.

The death cause or morbidity of their parents are dichotomous variables and are defined to be one if they either died from or have liver cancer, hepatitis or cirrhosis, and zero otherwise. Genetic characteristics which are not controlled by individuals may be captured and thus make ideal instruments.

Following Barsky, Juster, Kimball and Shapiro (1997), we construct the variables for time discount factor and risk aversion as follows. The question for time discount factor is: "What amount of money will you gain in ten years that is equivalent to the one million yen you currently get? And the question for risk 
aversion is: "What amount of money will you gain with $50 \%$ probability and with $50 \%$ probability you will not gain that is equivalent to the one million that you get now with certainty?" Let the response for the latter question be $x$ and assume utility function be in the exponential form. In this case, the relationship $100^{\alpha}=0.5 x^{\alpha}$ holds, and this indicates $\alpha=\log 2 /(\log x-\log 100)$. Thus risk aversion is defined by $-u^{\prime \prime}(c) c / u^{\prime}(c)=1-\alpha$. Time discount factor is calculated by $100^{\alpha}=\beta^{10} y^{\alpha}$ and thus $\beta=(100 / y)^{\alpha / 10}$ where $y$ is the response for the former question.

\section{Estimation Model}

Let $A_{i}$ be the level of alcohol consumption and $I_{i}$ be the labor productivity which is measured by labor income for the $i$ th individual. $X_{i}$ denotes independent variables which explain both the alcohol consumption and labor productivity, and $Y_{i}$ denotes instrument variables for alcohol consumption and that do not explain the labor productivity. Conversely, $Z_{i}$ denotes instrument variables for labor productivity and that do not affect alcohol consumption. Thus, we estimate

$$
\begin{aligned}
& \log A_{i}=\alpha+\alpha_{X} X_{i}+\alpha_{I} \log I_{i}+\alpha_{Y} Y_{i}+\varepsilon_{i} \\
& \log I_{i}=\beta+\beta_{X} X_{i}+\beta_{A} \log A_{i}+\beta_{Z} Z_{i}+v_{i}
\end{aligned}
$$

by using a three stage least square method (hereafter, we refer to it as 3SLS).

In particular, we use the quadratic function of age, income other than labor income, educational attainment, time discount factor, risk aversion rate, and self-assessed health. The quadratic function of age and self-assessed health is often used as an indicator for health condition and implies general human capital and health capital, respectively, in labor productivity. Income other than labor income determines marginal utility of income; i.e., the higher the other income, 
the lower the marginal utility of income. This other income captures the pure income effect excluding price effect. Educational attainment implies general human capital in labor productivity and level of knowledge about alcohol consumption. According to the serial health capital research literature (Grossman(2001)), it does imply efficiency in health investment and thus a highly educated person would be expected to be more healthy ceteris paribus.

The instrument variables for alcohol consumption are knowledge about the harm of alcohol, cause of death or morbidity in their parents, and the duration of drinking.

According to the Rational Addiction Model (Becker and Murphy(1988)), when the duration of drinking is longer, implying a high accumulation of drinking over time, the marginal utility of drinking rises and the individual needs more alcohol to make price equal the marginal utility of drinking. Hence, the duration of drinking increases alcohol consumption. However, the duration of drinking or drinking behavior may have affected labor productivity in the past, and may affect current labor productivity. In that case, the duration of drinking affects not only current alcohol consumption, but also current labor productivity. In this sense, it is not an ideal instrument. In the following analysis, we perform both cases where the duration of drinking is used and not used as an instrument for assessing alcohol consumption.

Next, the instrument variables for labor productivity are the quadratic function of tenure, the interaction of age and tenure, and employee size. These are very popular variables in the Mincer type wage function applied to the Japanese labor market.

Summary statistics are shown in Table 1. As shown below, the unit of alcohol consumption is one drink of sake, which is equivalent to $20 \mathrm{~g}$ pure alcohol. It indicates that only $5-6 \%$ of respondents have knowledge of the rigorous definition, 
but $18 \%$ have knowledge of the broad definition.

\section{Estimation Result}

The estimation results for drinking and labor productivity in the rigorous definition are summarized in Tables 2 and 3. Those of the broad definition are shown in Tables 4 and 5 .

Before evaluating the estimators, we must perform the Hausman test under the null hypothesis that Ordinary Least Square (OLS) is equivalent to Instrumental Variable Methods (IV). If this test result is not rejected, alcohol consumption/labor productivity is exogenous and thus we do not need to use IV and OLS is appropriate because it is more efficient than IV. Conversely, if the result is rejected, alcohol consumption/labor productivity is endogenous and thus we have to use IV because OLS is inconsistent. Almost all the test statistics, except for labor productivity in females under the broad definition, are very low and are not rejected. Moreover, Fstatistics in the first step, where the instrument variable regresses on endogenous variables, are lower than 10 except for male labor productivity. While we relax the criterion to be more than 8 , the estimation for alcohol consumption overcome these condition. In this case, labor productivity of female does not sufficient strong instruments (Bound, Jaeger and Baker(1995), Staiger and Stock(1997)). Therefore, these test statistics mean we should refer the estimation result in OLS for alcohol consumption in both gender and labor productivity in male, and we do not consider about labor productivity in female due to lack of appropriate instruments.

Let us evaluate the relationship of most concern, which is between alcohol consumption and labor productivity. The estimated estimator shows that labor productivity does not significantly affect alcohol consumption, but the reverse 
relationship is significantly positive except for males under the rigorous definition. Moreover, the estimated elasticity is less than 1 for males, but it is more than 1 for females. However, we have to remember that the female case is characterized by high endogeneity in labor productivity and weak instruments.

In alcohol consumption estimation other than labor productivity, it is an increasing concave function of age, with peaks at 50 years of age for males and 42 years of age for females. Only female medical school graduates practice risk aversion and decrease alcohol consumption. Healthy persons, whose self-assessed health condition is excellent, tend to drink more compared with those who report a fair or bad health condition.

The duration of drinking gradually increases the amount of drinking as the theory predicts. An additional 10 years of drinking experience raises the amount drunk by $22 \%$ in males and $12 \%$ in females. The cause of death or morbidity in parents is not significant. Conversely, the knowledge in the broad definition significantly reduces drinking. This result supports the strategy of Health Japan 21. Note that this does not imply causality in the rigorous sense. In other words, it is not clear in this estimation whether knowledge exactly reduced drinking or heavy drinkers justify their consumption levels as appropriate.

For estimation of labor productivity for effects other than alcohol consumption, tenure in males and age in females are significant. The reason for insignificance of age in males seems to be long-term employment in Japan and there is thus a high covariance of age and tenure. For males, other labor income is low when other income is high. This pattern appears to reflect part-time work of dependents of more than 20 years age. Low earnings for self-employed and part-time work is a matter of course. Health conditions do not affect labor productivity.

In order to check the robustness of the results obtained, we estimate another specification omitting duration of drinking as instrument variables ${ }^{2}$. The esti- 
mation results are summarized in Tables 6 and 7. Though omitting duration of drinking does not affect alcohol consumption, it affects the labor productivity result. Specifically, the estimated elasticity is more than 1 for males, but the Hausman test indicates that OLS is appropriate. For females, alcohol consumption does not significantly affect this specification.

\section{Concluding Remarks}

For males, OLS results with the Hausman test show the amount of drinking rises labor productivity significantly and its elasticity is about 0.13 . Conversely, female case is suffered from weak instruments and thus we cannot reach the form conclusion. The potential reason for this may be the small sample size, which is half that of males, and/or more heterogeneous than male. Thus, we cannot make conclusions about the female case and suggest further research.

Moreover, the knowledge of the harmful effects of alcohol reduces drinking by $20 \%$ in males and supports the Health Japan 21 strategy. On the other hand, labor productivity or income does not affect alcohol consumption.

Since this is the first investigation of drinking and labor productivity in Japan, the results obtained allow us to make only tentative conclusions. We need to check the robustness of our research by using other data, methods and instruments. 


\section{Footnotes}

*) This research is a part of the research project financed by the Japanese Ministry of Education and Science, the 2000 Scientific Research Grant, entitled "Evaluation for Economic Institutions Based on Empirical Research for Household Behavior" (grant number 12124207), headed by Prof. Fumio Hayashi of the University of Tokyo. We are grateful for the comments received from the participants in the project and Professor Tadashi Yamada of Tsukuba University. We would like to acknowledge the contributions of discussion and information provided to us by Wataru Senou. I would also like to acknowledge the assistance provided by Kazuko Matsumoto and Kunio Tsuyuhara.

1) Other than the relationship with labor supply, there is considerable empirical research on alcohol from the viewpoint of health economics. Baughaman, Colin, Dickert-Conlin, Pepper(2001) analyzed the effects of drinking regulations on traffic accidents and found that such a regulation increases the rate of accidents. On the other hand, Pinka and Markowitz(2001) could not establish a robust relationship between mothers' alcohol consumption and their children's behavior.

2) The estimation under another specification is performed in the broadly defined knowledge because it provides more interesting results in the above estimation. There is no substantial difference between the two definitions of knowledge. 


\section{References}

[1] Baughaman,R., M.Colin, S.Dickert-Conlin, and J.Pepper (2001), "Slippery When Wet: the Effects of Local Alcohol Access Laws on Highway Safety," Journal of Health Economics 20, pp.1089-1096.

[2] Becker,G.S., and K.M.Murphy (1988), "A Theory of Rational Addition," Journal of Political Economics 96,4, pp.675-700.

[3] Benham,L., and A.Benham (1982), "Employment, Earnings, and Psychiatric Diagnosis," Economic Aspects of Health, Fuchs.V.(ed). University of Chicago Press:Chicago, pp.203-220.

[4] Berger,M.C., and J.P.Leigh (1988), "The Effect of Alcohol Use on Wages," Applied Econnomics 20, 1343-1351.

[5] Bound,J., D.A.Jaeger, and R.M.Baker (1995), "Problems With Instrumental Variables Estimation When the Correlation Between the Instruments and the Endogenous Explanatory Variable Is Weak," Journal of the American Statistical Association pp.443-450.

[6] Bryant,R.R., V.A.Samaranayake, and A.Whilhite (1993), "The Influence of Current and Past Alcohol Use on Earnings: Three Approaches to Estimation," Journal of Applied Behavior Science 29, 9-31.

[7] Freeman,D.G. (1999), "A Note on Economic Conditions and Alcohol Problems," Journal of Health Economics 18, pp.661-670.

[8] French,M.T., and G.A.Zarkin (1995), "Is Moderate Alcohol Use Related to Wages? Evidence from Four Work-Sites," Journal of Health Econnomic 14, pp.319-344. 
[9] Grossman,M. (2001), "The Human Capital Model", in A.J.Culyer and J.P.Newhouse, eds, Handbook of Health Economics, Elsevier.

[10] Holman,C.D.J., D.R.English, E.Milne, et al. (1996), "Meta-Analysis of Alcohol and All-Cause Mortality: a Validation of NHMRC Recommendations," MJA 164, pp.141-145.

[11] Kenkel,D.S., and D.C.Ribar (1994), "Alcohol Consumption and Young Adults' Socioeconomic Status," Brookings Papers Econnomics Activity:Microeconomics 1, pp.119-161.

[12] Mullahy,J. and J.L.Sindelar (1993), "Alcoholism, Work, and Income," Journal of Labor Economics 11(3), pp.494-520.

[13] Pinka,C., and S.Markowitz (2001), "The Impact of Maternal Alcohol and Illicit Drug Use on Children's Behaviour Problems: Evidence from the Children of the National Longitudinal Survey of Youth," Journal of Health Economics 20, pp.703-731.

[14] Ruhm (1995),"Economic Conditions and Alcohol Problems," Journal of Health Economics 14, pp.583-603.

[15] Staiger,D., and J.H.Stock (1997), "Instrumental Variables regression With Weak Instruments," Econometrica 65(3), pp.557-586.

[16] Thomas,S. (2001), "Alcohol Abuse and Economic Condition: Evidence from Repeated Cross-Section of Individual-Level Date," Health Economics 10, pp.257-270.

[17] Tsugane,S., M.T.Fahey, S.Sasaki, et al. (1999), "Alcohol Consumption and All-Cause Cancer Mortality Among Middle-Aged Japanese Men: Seven Year 
Follow-Up of the JPHC Study Cohort I," American Journal of Epidemiology 150, pp.1201-1207.

[18] Zarkin,G.A., M.T.French, T.Mroz, et al. (1998), "Alcohol Use and Wages: New Results from the National Household Survey on Drug Abuse," Journal of Health Economics 17(1), pp.53-68.

[19] The Committee for Health Japan 21 (2000), Report for the National Movement of Health Promotion in the 21st Century (Health Japan 21).

[20] Sato,M., and Y.Ohkusa (2002), "An Empirical Research for Smoking Initiation in Japan," manuscript. 


\section{Table 1: Summary Statistics}

\begin{tabular}{lllll}
\hline & \multicolumn{2}{c}{ Male } & \multicolumn{2}{c}{ Female } \\
& Average & Std. Dev. & Average & Std. Dev. \\
\hline Labor Income(log) & 6.192261 & 1.088171 & 4.820081 & 1.068712 \\
Alcohol Cons.(log) & .999656 & .6083761 & .5379219 & .43564 \\
Age & 43.14043 & 11.91444 & 41.12286 & 12.49203 \\
Age $^{2}$ & 2002.832 & 1065.795 & 1846.694 & 1060.113 \\
Tenure & 14.64953 & 11.2756 & 7.338192 & 8.227178 \\
Tenure & 341.5498 & 436.1824 & 121.3382 & 264.8124 \\
Age·Tenure & 707.014 & 668.5376 & 356.4082 & 484.7816 \\
Other Income(log) & 2.464473 & 3.00303 & 6.044326 & 1.614122 \\
Education Attainment & & & & \\
Medical School & .0092879 & .0959996 & .0028653 & .0535288 \\
Other University & .495356 & .5003659 & .2091691 & .4072993 \\
Two Years College & .0263158 & .1601967 & .2406877 & .4281148 \\
Vocational School & .0928793 & .2904881 & .1232092 & .329149 \\
Time Discount Factor & .8859264 & .0754176 & .8915542 & .0760757 \\
Risk Aversion & .1334806 & .1545627 & .116444 & .1411296 \\
Self Assessed Health & & & & \\
Good & .3051643 & .4608377 & .3409742 & .4747173 \\
Fair & .5117371 & .5002538 & .5071633 & .5006665 \\
Poor & .0985915 & .2983464 & .1002865 & .3008129 \\
Very Poor & .0156495 & .1242123 & .008596 & .0924477 \\
Goverment Employee & .0740741 & .2620937 & .04 & .1962397 \\
Self Employed & .1450617 & .3524351 & .1228571 & .3287431 \\
Part Time Job & .0262346 & .1599556 & .5657143 & .4963724 \\
Firm Size(log) & 4.72599 & 2.28262 & 3.847275 & 2.122926 \\
Knowledge Level & .0524691 & .2231434 & .0628571 & .2430533 \\
Knowledge Level(2) & .1805556 & .3849467 & .1857143 & .3894327 \\
Morbidity in Parents & .1033951 & .3047094 & .0857143 & .2803425 \\
Drinking Duration & 21.57935 & 11.10908 & 16.46285 & 10.50488 \\
\hline & & & &
\end{tabular}

Note:Sample size is 643 in male and 350 in female. 
Table 2: Estimation Result in Alcohol Consumption

\begin{tabular}{lllll}
\hline & \multicolumn{2}{c}{ 3SLS } & \multicolumn{2}{c}{ OLS } \\
& Male & Female & Male & Female \\
\hline Labor Income(log) & .0097332 & .0456081 & .0286383 & .0260648 \\
Age & $.056246^{* * *}$ & $.0465336^{* * *}$ & $.0549352^{* * *}$ & $.0392732^{* *}$ \\
Age $^{2}$ & $-.0005727^{* * *}$ & $-.0005583^{* * *}$ & $-.0005536^{* * *}$ & $-.000472^{* * *}$ \\
Other Income(log) & .0046057 & -.0207122 & .0061013 & -.015491 \\
Education Attainment & & & & \\
Medical School & -.3922111 & $-.8569118^{*}$ & -.3857193 & $-.790234^{*}$ \\
Other University & -.0761214 & -.0433436 & $-.0954014^{*}$ & -.0234935 \\
Two Years College & .059898 & -.0273993 & .0441416 & -.0152943 \\
Vocational School & .0071876 & .0276715 & .0073094 & .0402326 \\
Time Discount Factor & -.0897377 & -.2899026 & -.0895623 & -.2491723 \\
Risk Aversion & .0974137 & $-.5957341^{* * *}$ & .1105082 & $-.5561271^{* * *}$ \\
Self Assessed Health & & & & \\
Good & -.1278031 & -.0823639 & -.1219897 & -.0820405 \\
Fair & $-.1716826^{*}$ & -.0779425 & $-.1627078^{*}$ & -.0719642 \\
Poor & $-.2050657^{*}$ & $-.2593828^{*}$ & $-.1923044^{*}$ & $-.2423169^{*}$ \\
Very Poor & -.1296732 & -.1225815 & -.1273477 & -.1113445 \\
Knowledge Level & -.0312078 & .0309553 & -.0237749 & .03618 \\
Morbidity in Parents & -.0157774 & .0545959 & -.0143534 & .0469279 \\
Drinking Duration & $.0221136^{* * *}$ & $.012405^{* * *}$ & $.0219188^{* * *}$ & $.0127898^{* * *}$ \\
constant & -.5462771 & -.3440808 & -.6367792 & -.1995851 \\
\hline Hausman Test & 7.71 & 6.63 & & \\
$p$-value & 0.73 & 0.25 & & \\
F stat(1st step) & 8.24 & 8.78 & & \\
$p$-value & $\leq 0.0000$ & $\leq 0.0000$ & & \\
F stat(2nd step) & 13.02 & 3.58 & 13.83 & 3.39 \\
$p$-value & $\leq 0.0000$ & $\leq 0.0000$ & $\leq 0.0000$ & $\leq 0.0000$ \\
$\bar{R} 2$ & 0.2674 & 0.1223 & 0.2757 & 0.1149 \\
\hline & & & & \\
\hline
\end{tabular}




\section{Table 3: Estimation Result in Labor Income}

\begin{tabular}{|c|c|c|c|c|}
\hline & \multicolumn{2}{|c|}{$3 \mathrm{SLS}$} & \multicolumn{2}{|c|}{ OLS } \\
\hline & Male & Female & Male & Female \\
\hline Alcohol Cons. $(\log )$ & .4599617 & $1.33893^{* *}$ & $.1339077^{*}$ & .1273949 \\
\hline Age & .0334321 & $-.130719^{* *}$ & $.062083^{*}$ & -.0397929 \\
\hline $\mathrm{Age}^{2}$ & -.0004334 & $.0014811^{* *}$ & $-.0006702^{*}$ & .0004646 \\
\hline Tenure & $.0512598^{*}$ & .0669202 & $.0538695^{* *}$ & .0439066 \\
\hline Tenure $^{2}$ & -.000096 & .000481 & -.0000653 & .0003651 \\
\hline Age $\cdot$ Tenure & -.0005259 & -.0010649 & -.0005863 & -.0005719 \\
\hline Other Income(log) & $-.0236258^{*}$ & .0589067 & -.0215961 & .029733 \\
\hline \multicolumn{5}{|l|}{ Education Attainment } \\
\hline Medical School & -.5278725 & 1.604901 & -.6628151 & .6584168 \\
\hline Other University & $.3512312^{* * *}$ & .0362669 & $.3287081^{* * *}$ & .0089018 \\
\hline Two Years College & .2665785 & -.1400049 & .2660608 & -.1750401 \\
\hline Vocational School & .1716071 & .0717846 & .1703461 & .156441 \\
\hline Time Discount Factor & .2917005 & 1.134021 & .3035178 & .8768537 \\
\hline Risk Aversion & -.0318548 & $.8479043^{*}$ & .0156771 & .1944511 \\
\hline \multicolumn{5}{|l|}{ Self Assessed Health } \\
\hline Good & -.1904141 & .1793413 & -.2425456 & .070973 \\
\hline Fair & -.0311075 & .1418404 & -.1002714 & .0210541 \\
\hline Poor & -.0150414 & .5538471 & -.0891181 & .2070738 \\
\hline Very Poor & .0616582 & .7434778 & -.0040772 & .6167716 \\
\hline Goverment Employee & -.0884288 & .36709 & -.1064286 & .3264826 \\
\hline Self Employed & $-.3363858^{* *}$ & $-1.149695^{* * *}$ & $-.2849229^{* *}$ & $-1.113089^{* * *}$ \\
\hline Part Time Job & $-.7700529^{* * *}$ & $-1.054122^{* * *}$ & $-.7598206^{* * *}$ & $-1.174005^{* * *}$ \\
\hline Firm Size(log) & .0401534 & .0124207 & $.0421536^{*}$ & .0150725 \\
\hline constant & $4.388965^{* * *}$ & $5.78408^{* * *}$ & $3.993381^{* * *}$ & $5.115168^{* * *}$ \\
\hline Hausman Test & 4.95 & 6.63 & & \\
\hline$p$-value & 0.9989 & 0.2496 & & \\
\hline F stat(1st step) & 14.56 & 3.53 & & \\
\hline$p$-value & $\leq 0.0000$ & $\leq 0.0000$ & & \\
\hline F stat(2nd step) & $\overline{7} .04$ & $\overline{6} .61$ & 7.45 & 9.00 \\
\hline$p$-value & $\leq 0.0000$ & $\leq 0.0000$ & $\leq 0.0000$ & $\leq 0.0000$ \\
\hline $\bar{R}^{2}$ & 0.1626 & 0.0862 & 0.1929 & 0.3523 \\
\hline
\end{tabular}


Table 4: Estimation Result in Alcohol Consumption under Another Information Definition

\begin{tabular}{lllll}
\hline & \multicolumn{2}{c}{ 3SLS } & \multicolumn{2}{c}{ OLS } \\
& Male & Female & Male & Female \\
\hline Labor Income(log) & -.0024074 & .0478219 & .024915 & .0270465 \\
Age & $.055175^{* * *}$ & $.0454807^{* * *}$ & $.0529184^{* * *}$ & $.0380158^{* *}$ \\
Age $^{2}$ & $-.0005533^{* * *}$ & $-.0005416^{* * *}$ & $-.0005244^{* * *}$ & $-.0004524^{* *}$ \\
Other Income(log) & .0058485 & -.0200375 & .0075709 & -.0153611 \\
Education Attainment & & & & \\
Medical School & $-.4313849^{*}$ & $-.8079828^{*}$ & $-.4185234^{*}$ & $-.7278953^{*}$ \\
Other University & -.083297 & -.0462229 & $-.1047405^{* *}$ & -.0278087 \\
Two Years College & .0337495 & -.0292963 & .0137051 & -.0186063 \\
Vocational School & -.002611 & .0307527 & -.0032938 & .043636 \\
Time Discount Factor & -.1510412 & -.269825 & -.1550303 & -.2203742 \\
Risk Aversion & .1052713 & $-.5938243^{* * *}$ & .1176636 & $-.5539879^{* * *}$ \\
Self Assessed Health & & & & \\
Good & -.132076 & -.0912049 & -.124683 & -.0910628 \\
Fair & $-.1814609^{* *}$ & -.0865325 & $-.1724246^{*}$ & -.0820336 \\
Poor & $-.2048198^{*}$ & $-.2548128^{*}$ & $-.1912336^{*}$ & $-.2370446^{*}$ \\
Very Poor & -.153765 & -.144767 & -.1496814 & -.1369673 \\
Knowledge Level & $-.1524088^{* *}$ & -.0626086 & $-.1522299^{* *}$ & -.0777138 \\
Morbidity in Parents & -.00885 & .0509993 & -.0065359 & .0452682 \\
Drinking Duration & $.0217493^{* * *}$ & $.0122161^{* * *}$ & $.0215486^{* * *}$ & $.0125643^{* * *}$ \\
constant & -.3673267 & -.3395605 & -.4855488 & -.1851095 \\
\hline Hausman Test & 7.24 & 6.18 & & \\
$p$-value & 0.7790 & 0.2889 & & \\
F stat(1st step) & 8.24 & 8.78 & & \\
$p$-value & $\leq 0.0000$ & $\leq 0.0000$ & & \\
F stat(2nd step) & 13.51 & 3.64 & 14.37 & 3.49 \\
$p$-value & $\leq 0.0000$ & $\leq 0.0000$ & $\leq 0.0000$ & $\leq 0.0000$ \\
$\bar{R}^{2}$ & 0.2739 & 0.2748 & 0.2840 & 0.1192 \\
\hline & & & & \\
\hline
\end{tabular}


Table 5: Estimation Result in Labor Income under Another Information Definition

\begin{tabular}{|c|c|c|}
\hline & \multicolumn{2}{|c|}{$3 \mathrm{SLS}$} \\
\hline & Male & Female \\
\hline Alcohol Cons.(log) & $.6096822^{*}$ & $1.2654^{* *}$ \\
\hline Age & .0209581 & $-.1252006^{* *}$ \\
\hline $\mathrm{Age}^{2}$ & -.0003307 & $.0014195^{* *}$ \\
\hline Tenure & $.0508204^{*}$ & .0655234 \\
\hline Tenure $^{2}$ & -.0000979 & .000474 \\
\hline Age·Tenure & -.0005232 & -.001035 \\
\hline Other Income(log) & $-.0241065^{*}$ & .0571361 \\
\hline \multicolumn{3}{|l|}{ Education Attainment } \\
\hline Medical School & -.4628512 & 1.547458 \\
\hline Other University & $.3605664^{* * *}$ & .0346061 \\
\hline Two Years College & .2670884 & -.1421312 \\
\hline Vocational School & .1697773 & .0769225 \\
\hline Time Discount Factor & .2996624 & 1.118413 \\
\hline Risk Aversion & -.0503578 & .8082451 \\
\hline \multicolumn{3}{|l|}{ Self Assessed Health } \\
\hline Good & -.1666308 & .1727643 \\
\hline Fair & -.0026433 & .1345097 \\
\hline Poor & .0178674 & .5328008 \\
\hline Very Poor & .0917028 & .7357878 \\
\hline Goverment Employee & -.0795142 & .3646255 \\
\hline Self Employed & $-.3539808^{* *}$ & $-1.147473^{* * *}$ \\
\hline Part Time Job & $-.7726295^{* * *}$ & $-1.061398^{* * *}$ \\
\hline Firm Size(log) & .0402156 & .0125816 \\
\hline constant & $4.539304^{* * *}$ & $5.743483^{* * *}$ \\
\hline Hausman Test & 6.93 & 51.05 \\
\hline$p$-value & 0.9907 & 0.0001 \\
\hline F stat(1st step) & 15.17 & 3.63 \\
\hline$p$-value & $\leq 0.0000$ & $\leq 0.0000$ \\
\hline F stat(2nd step) & 6.86 & 7.45 \\
\hline$p$-value & $\leq 0.0000$ & $\leq 0.0000$ \\
\hline $\bar{R}^{2}$ & 0.1616 & 0.1929 \\
\hline
\end{tabular}




\section{Table 6: Estimation Result in Alcohol Consumption (excluding Drinking Duration)}

\begin{tabular}{lllll}
\hline & \multicolumn{2}{c}{ 3SLS } & \multicolumn{2}{c}{ OLS } \\
& Male & Female & Male & Female \\
\hline Labor Income(log) & -.0409866 & .0468702 & .0240276 & .0380364 \\
Age & $.0861011^{* * *}$ & $.0628476^{* * *}$ & $.0784957^{* * *}$ & $.0574183^{* * *}$ \\
Age $^{2}$ & $-.0006918^{* * *}$ & $-.0006596^{* * *}$ & $-.0006083^{* * *}$ & $-.0005905^{* * *}$ \\
Other Income(log) & .002604 & -.0262538 & .0059179 & -.0207335 \\
Medical School & $-.5285812^{* *}$ & -.6925939 & $-.4877068^{* *}$ & -.6271804 \\
Other University & -.0700843 & -.0226112 & $-.1054648^{* *}$ & -.0057627 \\
Two Years College & -.0228453 & -.0125181 & -.0596032 & -.0001838 \\
Vocational School & .0216982 & .078558 & .0102068 & .091081 \\
Time Discount Factor & -.1687941 & -.2832074 & -.1809854 & -.2459426 \\
Risk Aversion & .1329646 & $-.5299202^{* * *}$ & .1384802 & $-.4923349^{* * *}$ \\
Good & $-.1751032^{*}$ & -.1072791 & $-.1590201^{*}$ & -.112374 \\
Fair & $-.2149321^{* *}$ & -.1043509 & $-.2012263^{* *}$ & -.1045483 \\
Poor & $-.2197496^{*}$ & $-.2962287^{* *}$ & $-.2061258^{*}$ & $-.2825446^{* *}$ \\
Very Poor & -.213145 & -.1748202 & -.1983901 & -.1765419 \\
Knowledge Level & $-.1886683^{* * *}$ & -.0692067 & $-.1785905^{* * *}$ & -.0861231 \\
Morbidity in Parents & -.0194316 & .0783688 & -.0187921 & .0719122 \\
constant & -.653976 & -.5691712 & $-.8857697^{* *}$ & -.5025754 \\
\hline Hausman Test & 7.38 & 5.89 & & \\
$p$-value & 0.7676 & 0.3170 & & \\
F stat(1st step) & 8.24 & 8.78 & & \\
$p$-value & $\leq 0.0000$ & $\leq 0.0000$ & & \\
F stat(2nd step) & 12.29 & 2.77 & 13.29 & 2.69 \\
$p$-value & $\leq 0.0000$ & 0.0004 & $\leq 0.0000$ & 0.0005 \\
$\bar{R}^{2}$ & 0.2338 & 0.0864 & 0.2748 & 0.0794 \\
\hline
\end{tabular}




\section{Table 7: Estimation Result in Labor Income (excluding Drinking Duration )}

\begin{tabular}{|c|c|c|}
\hline & \multicolumn{2}{|c|}{ 3SLS } \\
\hline & Male & Female \\
\hline Alcohol Cons.(log) & $1.30437^{*}$ & 1.226542 \\
\hline Age & -.0334041 & -.1222843 \\
\hline $\mathrm{Age}^{2}$ & .0001083 & .0013868 \\
\hline Tenure & .0495371 & .0647853 \\
\hline Tenure $^{2}$ & -.0000707 & .0004703 \\
\hline Age.Tenure & -.0005476 & -.0010192 \\
\hline Other Income(log) & -.0227749 & .0562004 \\
\hline Medical School & -.1597815 & 1.517101 \\
\hline Other University & $.3981458^{* * *}$ & .0337284 \\
\hline Two Years College & .2725888 & -.1432549 \\
\hline Vocational School & .1363394 & .0796377 \\
\hline Time Discount Factor & .427949 & 1.110165 \\
\hline Risk Aversion & -.1119825 & .7872871 \\
\hline Good & -.0488073 & .1692886 \\
\hline Fair & .124932 & .1306357 \\
\hline Poor & .1693323 & .5216789 \\
\hline Very Poor & .2370051 & .731724 \\
\hline Goverment Employee & -.046888 & .3633231 \\
\hline Self Employed & $-.4186798^{* *}$ & $-1.146299^{* * *}$ \\
\hline Part Time Job & $-.7743614^{* *}$ & $-1.065243^{* * *}$ \\
\hline Firm Size(log) & .0458329 & .0126667 \\
\hline constant & $5.055997^{* * *}$ & $5.722029^{* * *}$ \\
\hline Hausman Test & 8.13 & 43.99 \\
\hline$p$-value & 0.9449 & 0.0003 \\
\hline F stat(1st step) & 14.08 & 2.70 \\
\hline$p$-value & $\leq 0.0000$ & 0.0007 \\
\hline F stat(2nd step) & 5.09 & 6.72 \\
\hline$p$-value & $\leq 0.0000$ & $\leq 0.0000$ \\
\hline $\bar{R}^{2}$ & 0.1584 & 0.1333 \\
\hline
\end{tabular}

